\title{
LEPRA, EXAGERACIÓN Y AUTORIDAD MÉDICA
}

\author{
Diana Obregón* \\ Departamento de Historia - Facultad de Ciencias Humanas \\ Universidad Nacional de Colombia - Bogotá D. C. (Colombia)
}

\section{RESUMEN}

En este artículo se analiza la reacción de los médicos colombianos de finales del siglo XIX frente a lo que ellos consideraron el aumento del número de enfermos de lepra en Colombia. Basándose en un censo defectuoso, los médicos exageraron los datos de contagiados con el fin de medicalizar la enfermedad, puesto que en esa época el cuidado de los enfermos estaba en manos de organizaciones filantrópicas. Se examina la actitud de los médicos frente a la lepra en relación con la necesidad de reforzar su autoridad cultural, desplegando su competencia científica frente a otros grupos sociales y de construir una medicina nacional que les diese visibilidad a nivel internacional. Los médicos encontraron justificación adicional para su actitud en las nuevas teorías bacteriológicas, que calificaban a la lepra como una enfermedad altamente contagiosa y peligrosa. En este mismo período, la medicina se convirtió en una profesión en Colombia: se estabilizó su enseñanza en la Universidad Nacional y se crearon sociedades y academias médicas que contribuyeron a la profesionalización de la actividad. Por lo tanto, la lepra fue utilizada por la comunidad médica colombiana en el proceso de construir su autoridad y de aumentar su poder profesional.

\section{SUMMARY}

In this article I analyze the reaction of Colombian physicians in the late nineteenth century towards what they saw as the growing number of people infected with leprosy in Colombia. Based on an incomplete census, doctors exaggerated the number of infected people to medicalize the disease because the care of patients was in the hands of philanthropic institutions. I examine the attitude of doctors as related to their perceived need of reinforcing their cultural authority, displaying their scientific competence in front of other social groups, and building a national medicine that would give them visibility in the international arena. Physicians found further justification in new bacteriological theories which conceptualized leprosy as a highly contagious and dangerous disease. In this period, medicine became a profession in Colombia: its teaching became stabilized in the National University and the doctors created societies and academies which contributed to their professionalizacion. Therefore, leprosy was used by the Colombian medical community in its process of building their scientific authority and enlarging their professional power.

* Agradezco a Javier Ordóñez, de la Universidad Autónoma de Madrid, su gentil invitación a consultar bibliotecas españolas para esta investigación. 


\title{
DIANA OBREGÓN
}

\begin{abstract}
"Esplendorosa gloria se reflejaría en el gobierno que llegara a establecer los lazaretos en Colombia, porque ésta es la primera necesidad de la Nación, puesto que las consecuencias de este azote en el futuro son más terribles que aquellas de la guerra civil y de cualquiera otra causa de retroceso y barbarie".
\end{abstract}

Introducida supuestamente por los conquistadores españoles, objeto de atención por parte de los gobiernos tanto coloniales como republicanos y con frecuencia confundida con la sífilis y con otras enfermedades, la lepra ha ocupado un lugar especial en la historia de Colombia ${ }^{2}$. Siguiendo una costumbre medieval, durante la colonia los leprosos o elefancíacos eran segregados en el hospital de San Lázaro de Cartagena construido a comienzos del siglo XVII. La tradición de aislar a los enfermos de lepra continuó durante el período republicano más en la teoría que en la práctica por la dificultad para construir hospitales para lazarinos en las regiones donde la lepra era endémica ${ }^{3}$. Hacia el decenio de 1870 , los enfermos encontraron refugio en dos lazaretos cuyos terrenos habían sido apropiados por los gobiernos de los estados soberanos de Cundinamarca y. Santander. Un tercer lazareto, Caño de Loro, se instaló en lo que había sido el viejo hospital de San Lázaro trasladado a las cercanías de Cartagena.

De acuerdo con la literatura médica de la época, la expansión de la lepra alcanzó vastas proporciones hacia 1890. Sin embargo, el análisis histórico muestra que los médicos exageraron las dimensiones del problema: por una parte, aumentaron el número de enfermos basados en el dato inicial de contagiados arrojado por un censo deficiente, y por otra; exageraron la peligrosidad de la lepra calificándola como una enfermedad altamente contagiosa. El pánico creado por los médicos tenía como objetivo medicalizar la enfermedad puesto que hasta entonces la lepra no era un asunto propiamente médico. El manejo de los lazaretos y el cuidado de los enfermos estaba en manos de comunidades religiosas y de organizaciones de caridad. En este trabajo se examina la reacción de los médicos frente a la expansión de la enfermedad en función de los intereses de la profesión médica misma y de la necesidad de afirmar su autoridad cultural. De acuerdo con el sociólogo Paul Starr, la noción de autoridad cultural se refiere al poder social que posee un grupo basado en la probabilidad de que sus definiciones de la realidad y sus juicios de significado y de valor serán tomados como válidos y verdaderos ${ }^{4}$. De manera semejante, el sociólogo Pierre Bour-

1 NiCANOR G., InSIGNARES S., (1898) citado por Carlos Michelsen U., "La lepra," Revista Médica, 21 (232):1-29, pp. 12-13.

2 Aunque hoy en día, en varios países se considera impropio el uso de términos como "lepra" y "leproso", es preciso admitir que en el período considerado en este trabajo, esas palabras eran de uso corriente. En este sentido histórico se usarán aquí.

3 En España, desde tiempos medievales, la lepra fue llamada también elefancia, elefantiasis o mal de San Lázaro. A los leprosos se les conocía como elefancíacos o lazarinos, además de algunos otros nombres.

4 STARR, P., (1982) The Social Transformation of American Medicine: The Rise of a Sovereign Profession and the Making of a Vast Industry (New York: Basic Books), pp. 13-15. 
dieu define autoridad científica como el poder de hablar y de actuar de una manera autorizada y autoritaria acerca de cuestiones científicas 5 . En este artículo, se analiza el proceso por medio del cual los médicos colombianos, como grupo profesional, afirmaron su autoridad médica eliminando cualquier trazo de legitimidad que otros grupos pudieran tener para referirse al tema de la lepra.

\section{LA PROFESIÓN MÉDICA}

Había muy pocos médicos en la Colombia del siglo XIX (llamada Nueva Granada hasta 1863). En 1837 existían trece cátedras de medicina en el país; sin embargo, la mayoría de ellas se enseñaban en los colegios de las provincias donde había pocos recursos. ${ }^{6}$ Estos cursos no proporcionaban un entrenamiento médico adecuado; por lo tanto, quienes estaban interesados en una carrera de medicina y poseían los recursos viajaban a Europa para sus estudios. Como en la mayoría de cuestiones intelectuales, los estudiantes preferían ir a Francia para obtener educación científica y técnica. Otra forma de adelantar una carrera médica era estudiar en forma privada con un médico practicante. ${ }^{7}$ Sin embargo, debido a que el mercado para los médicos era limitado, pocos se sentían inclinados a proseguir estudios de medicina. Los 174 médicos acreditados por la Facultad de Medicina de Bogotá para atender a uná población de 1.200 .000 parecían excesivos a observadores contemporáneos ${ }^{8}$. Un médico por cada 7,350 habitantes era considerado un lújo para un país como la Nueva Granada. Por esta razón y por motivos políticos, Mariano Ospina Rodríguez, secretario de lo Interior (1841-1845), lanzó una reforma educativa como una manera de controlar el número de profesionales. De acuerdo con la reforma, solamente tres universidades, en Bogotá, Cartagena y Popayán, estarían autorizadas para otorgar grados profesionales en derecho y medicina. Los colegios de las provincias deberían enseñar únicamente materias técnicás, que en la Nueva Granada eran consideradas de baja jerarquía 9 .

5 BourdieU, P., (1975) "The Specificity of the Scientific Field and the Social Conditions of the Progress of Reason," Social Science Information, 14 (6):19-47, p. 19.

6 SAfFord, F., (1976) The Ideal of the Practical: Colombia's Struggle to Form a Technical Elite (Austin: Texas University Press), pp. 105, 110.

7 Miranda CANAL, N., (1993) "La medicina colombiana de 1867 a 1946," Historia Social de la Ciencia en Colombia vol. 8 (Bogotá: Tercer Mundo), pp. 13-160, en pp. 58-59; ver también: IBÁÑEZ, P. M., (1884) Memorias para la historia de la medicina en Santafé de Bogotá (Bogotá: Zalamea hermanos,), pp. 96-7.

8 YounG, J., L. (1970) "University Reform in New Granada, 1820-1850" Ph. D. Dissertation, Columbia University, p. 127.

9 SAFFORD, The Ideal of the Practical, pp. 116-123; RESTREPO, O., (1993) "Naturalistas, saber y sociedad en Colombia," Historia Social de la Ciencia en Colombia vol. 3 (Bogotá: Tercer Mundo), pp. 13-327, en pp. 239-242. 


\section{DIANA OBREGÓN}

Como una reacción a estas restricciones, el gobierno liberal de José Hilario López (1849-1853) aprobó en 1850 una ley que establecía completa libertad para enseñar y ejercer medicina, derecho e ingeniería y abolió el requisito del diploma profesional para la práctica de estas profesiones liberales ${ }^{10}$. Esta reforma, comparable a la abolición de las regulaciones médicas en Francia en 1792-1794, era parte de una fuerte oposición liberal a cualquier tipo de monopolio, fuese económico, social o político"1 . Las regulaciones académicas eran vistas como barreras que debían ser eliminadas. Como los títulos académicos eran sólo opcionales para la enseñanza o la práctica de la medicina, muy pocos estaban interesados en su estudio formal. Como resultado, las facultades de medicina existentes en Bogotá, Cartagena y Popayán fueron prácticamente aniquiladas. La ley de 1850 revela el poder tan limitado de los médicos neogranadinos como grupo profesional a mediados del siglo XIX.

El régimen liberal radical (1863-1880) revirtió las medidas de mediados de siglo y decidió promover vigorosamente la educación pública, creando la Universidad Nacional de los Estados Unidos de Colombia en 1867. Esta universidad incluía una escuela de medicina y ciencias naturales. De hecho, la universidad incorporó una escuela privada de medicina que había fundado en 1864 Antonio Vargas Reyes, médico graduado de la Facultad de Medicina de París. La escuela de medicina de la Universidad Nacional junto con la Sociedad de Medicina y Ciencias Naturales de Bogotá creada en 1873 y la Revista Médica (1873-1922) se convirtieron en los puntos de partida de la profesionalización de la medicina en Colombia. El gobierno aprobó las primeras reglamentaciones sobre la práctica de la profesión en 1887 y la Sociedad de Medicina se convirtió en Academia Nacional de Medicina en 1891. Los médicos de otras regiones también fundaron numerosas sociedades profesionales locales, entre ellas, la Academia de Medicina de Medellín organizada en 1887 y la Sociedad de Medicina del Cauca creada en 1889. Estas sociedades publicaron revistas de medicina, cirugía e higiene. A partir de 1893, los médicos colombianos realizaron congresos nacionales de medicina donde se discutieron cuestiones relacionadas con enfermedades epidémicas y endémicas, higiene y regulación del ejercicio de la medicina y de la farmacia ${ }^{12}$.

Aunque no existen estudios específicos sobre la profesionalización de la medicina en Colombia, basándose en la información disponible sobre la sociedad y la economía colombianas, se puede deducir que el mercado para los médicos era limitado. Hacia finales del siglo XIX, Colombia se caracterizaba por una economía basada en

\footnotetext{
10 Sobre las reformas liberales, ver: ESCOBAR RODRÍGUEZ, C., (1990) La revolución liberal y la protesta del artesanado (Bogotá: FUAC y Suramérica).

11 Sobre el caso francés, ver: RAMSEY, M., (1988) Professional and Popular Medicine in France, 1770-1830: The Social World of Medical Practice (Cambridge: Cambridge University Press), pp. 74-75.

12 OBRegón TORRES, D., (1992) Sociedades Científicas en Colombia: La invención de una tradición, 1859-1936 (Bogotá: Banco de la República), pp. 51-68.
} 
la agricultura, escasa participación en el comercio internacional, fragmentación regional e inestabilidad política. La población se encontraba dispersa en pequeños pueblos separados por una topografía compleja, con pobres vías de comunicación entre sí. En estas condiciones, se puede suponer que la clientela de los médicos era pequeña y se componía especialmente de pacientes ricos, aunque por lo general, los médicos atendían a los pobres como parte del ejercicio de la caridad cristiana ${ }^{13}$.

Hacia finales del siglo XIX, los médicos organizados en asociaciones médicas comenzaron a orientar sus actividades más hacia el grupo profesional que hacia sus propios pacientes. La investigación científica se convirtió en uno de los medios para adquirir prestigio dentro de la profesión ya que estas academias y sociedades estimulaban el estudio del diagnóstico, clasificación y causa de las enfermedades locales. Las revistas profesionales no solamente difundían conocimiento científico a través de traducciones de revistas médicas europeas y norteamericanas, sino que animaban a los médicos para que publicaran casos clínicos, observaciones y diagnósticos. ${ }^{14} \mathrm{Su}$ objetivo más importante era conformar una medicina nacional que estudiara las enfermedades y su relación con las diversas regiones, climas, altitudes, hábitos alimenticios y costumbres de los habitantes. Esta medicina debía ser parte de la medicina científica "universal" y, al mismo tiempo, parte integral de la construcción de la nación ${ }^{15}$. Ésta era la contribución de la profesión al proyecto civilizador de las élites; así como sus pares franceses, los médicos colombianos entendían su tarea como una "misión civilizadora"16. Estudiantes colombianos en Francia e Inglaterra informaban a sus colegas en Colombia sobre los debates médicos de actualidad. Entre los temas preferidos estaban las controversias de la Academia de Medicina de París sobre la teoría microbiana ${ }^{17}$. Pero también en Europa se discutía sobre enfermedades que los médicos colombianos encontraban en su propio territorio. Carlos E.

13 Emilio Quevedo y sus colegas aluden brevemente a la cuestión del mercado para los médicos a comienzos del siglo XX, en el período de construcción de las vías férreas en Colombia. De acuerdo con ellos, la clientela de los médicos estaba formada fundamentalmente por cultivadores de café, miembros del incipiente grupo de industriales, funcionarios del gobierno y trabajadores de los ferrocarriles. QUEvedo VÉLEZ, E., et al., (1993) "Ciencias médicas, estado y salud en Colombia: 1886-1957," Historia Social de la Ciencia en Colombia vol. 8 (Bogotá: Tercer Mundo), pp. 161-289, en p. 179.

14 Traducciones de la Revue des Sciences Médicales, Lancet, British Medical Journal, y Philadelphia Medical Times, entre otras revistas eran comunes en los periódicos médicos colombianos. Ver: NiCOLlE, Ch., (1905) "Reproducción experimental de la lepra en el mono," (de la Revue pratique des maladies cutanés, syphilitiques et vénériennes) Revista Médica, 25 (299):247-50; y SINCLAIR BLACK, R., (1907) "Nuevo aspecto de la patología y tratamiento de la lepra" (de The Lancet) Revista Médica, 27 (321): $177-81$.

15 OBREGón, Sociedades Científicas en Colombia, pp. 56, 77-79.

16 LABERGE, A., (1992) Mission and Method: The Early Nineteenth-Century French Public Health Movement (Cambridge: Cambridge University Press), p. 42.

17 Ver por ejemplo una carta de Juan E. Manrique informando desde París sobre las discusiones acerca de la teoría microbiana: Revista Médica, 1883, 8 (86):42-43. 


\section{DIANA OBREGÓN}

Putnam escribió en 1882 un informe sobre un estudio anatomo-patológico de un paciente que murió de lepra en el Hôtel-Dieu de Lyon y Daniel E. Coronado resumió en 1884 para la Revista Médica las lecciones que Jonathan Hutchinson dió sobre la lepra en el Colegio Real de Cirujanos de Inglaterra ${ }^{18}$. Con el fin de incrementar su prestigio profesional, los médicos buscaban reconocimiento en los centros médicos europeos, en particular en Francia. Por lo demás, médicos con un diploma de una escuela europea o que hubieran publicado en París tenían gran reputación en Colombia ${ }^{19}$.

De esta manera, la medicina colombiana comenzó a convertirse en una ocupación profesional a finales del siglo XIX. ${ }^{20}$ Los médicos como grupo organizado podían afirmar que poseían habilidades técnicas especiales que les permitían comprender el funcionamiento del cuerpo humano. Solamente ellos poseían la legitimidad necesaria para referirse a cuestiones definidas como médicas. Una parcela de la realidad era de su exclusivo dominio; la lepra pertenecía a ella: por lo tanto, curanderos, monjas o abogados debían abstenerse de opinar. En una palabra, los médicos comenzaron a construir su autoridad cultural.

\section{LA LEPRA: ENFERMEDAD CONTAGIOSA}

Por la época en que los médicos colombianos se ocupaban de organizar sociedades científicas, su colega noruego Gerhard Armauer Hansen (1841-1912) identificaba lo que posteriormente sería llamado Mycobacterium leprae como el agente etiológico de la lepra. En efecto, Hansen mencionó por primera vez sus observaciones del bacilo que sospechaba era la causa específica de la lepra en su informe anual a la Sociedad Médica de Christiania en $1874^{21}$. Además de una disputa por la prioridad sobre el "descubrimiento" 22 del bacilo de la lepra con el bacteriólogo alemán Albert

18 Putnam, C. E., (1882) "Estudio anatomo-patológico de la lepra de los griegos," Revista Médica, 7 (75):121-4; y CORONADO, D. E., (1884) "Lepra," Revista Médica, 8 (94):419-21.

19 MIRANDA, "La Medicina Colombiana," pp. 58-66.

20 Sobre procesos semejantes de profesionalización de la medicina en Inglaterra, Francia y los Estados Unidos, ver: WAdDINGTON, I., (1984) The Medical Profession in the Industrial Revolution (Dublin: Gill and Macmillan Humanities Press), pp. 191-4; GOUBERT J.-P., (1982) (ed.), La Médicalisation de la Société Française 1770-1830 (Waterloo, Historical Reflections Press) y STARR, P., (1982) The Social Transformation of American Medicine: The Rise of a Sovereign Profession and the Making of a Vast Industry (New York: Basic Books).

21 HANSEN, G. A., (1874) "Undersogelser angaaende Spedalskhedens Aarsager," Norsk Magazin for Laegevidenskaben, , 9:1-88, reimpreso en 1955 como "Causes of Leprosy," International Journal of Leprosy 23 (3): 307-9.

22 Aquí se toma la noción de descubrimiento en el sentido sociológico de construcción social más que en el sentido naturalista de "revelación" de los secretos de la naturaleza. Sin embargo, no es el propósito de este artículo profundizar en esta discusión. Ver: BRANNIGAN, A., (1981) The Social Basis of Scientific Discoveries (Cambridge: Cambridge University Press). 
Neisser, fue necesario esperar los datos epidemiológicos de la expansión de la lepra en las islas del Pacífico para que la teoría contagionista de Hansen fuese aceptada oficialmente ${ }^{23}$. La idea de que la lepra se transmitía por herencia era la teoría dominante sobre el origen de la enfermedad. Esta teoría había sido enunciada por los médicos noruegos Daniel C. Danielssen y Carl W. Boeck en 1847 y era compartida por figuras tan prestigiosas como el patólogo alemán Rudolf Virchow ${ }^{24}$. Debido a que el "bacilo de Hansen" no satisfacía los tres postulados de Koch (aislamiento, cultivo e inoculación) no existía la comprobación bacteriológica de que éste era en efecto el agente etiológico de la lepra. Sin embargo, la rápida difusión de la lepra en Hawai y el pánico originado en Europa y en los Estados Unidos por el contagio de lepra y muerte del célebre sacerdote belga Joseph Damien de Veuster en la isla-leprosario de Molokai en 1889, contribuyeron a que la teoría del contagio ganara adeptos entre las comunidades médicas. La aceptación oficial de que ésta era una enfermedad contagiosa producida por un microorganismo específico tuvo lugar en el primer congreso internacional sobre la lepra celebrado en Berlín en 1897 y fue el producto de una negociación entre bacteriólogos y epidemiólogos ${ }^{25}$.

En Colombia, los médicos no solamente siguieron con interés los debates sobre la lepra, sino que participaron aportando su experiencia y conocimiento sobre el tema. La necesidad de construir un conocimiento universal hacía de las sociedades médicas los foros apropiados para estas discusiones. En 1882, Gabriel J. Castañeda, de la Sociedad de Medicina de Bogotá, publicó una de las primeras descripciones de la lepra desde el punto de vista de la teoría microbiana, realizadas en Colombia ${ }^{26}$. Las discusiones que tuvieron lugar en 1885 y en 1888 en la Academia de Medicina de París sobre la contagiosidad de la lepra fueron traducidas y publicadas en la Revista Médica, así como una versión en castellano de la traducción inglesa de 1895 de uno de los trabajos de Hansen ${ }^{27}$. De otra parte, resultaba importante establecer si dolencias conocidas con nombres tales como mal de San Antonio, siringomielia o enfer-

23 Ver OBREGón, D., (1997) "Struggling Against Leprosy: Physicians, Medicine and Society in Colombia, 1880-1940" Ph.D. Dissertation, Virginia Polytechnic Institute and State University, capítulo 3.

24 DANIELSSEN D. C. and BOECK, C. W. (1848) Traité de la Spedalsked ou Eléphantiasis des Grecs Monograph (Paris: J.B. Ballière); también: Atlas de la Lèpre par D.C. Danielssen et C.W. Boeck, Bergen en Norvèege, 1847 Édition commemorative du centenaire ed. by Héraclídes-Cesar de Souza-Araujo (Rio de Janeiro, 1946).

${ }^{25}$ Estos temas se discuten más ampliamente en: OBREGón, "Struggling Against Leprosy", capítulo 3.

26 CASTAÑEDA, G. J., (1882) Causa y tratamiento racional de la lepra de los griegos hallados por inducción (Bogotá: Imprenta de Echeverría hermanos).

27 "Discussion sur la contagiosité de la lèpre," Bulletin de l'Académie de Médecine, 1885, 14 (42):1396-1414. "Naturaleza contagiosa de la lepra," Revista Médica, 1889, 12 (134):337-338; "Sur la nature contagieuse de la lèpre," Bulletin de l'Académie de Médecine, 1888, 20 (48):751-752. "La lepra en sus aspectos clínicos y patológicos". Por el doctor Armauer Hansen y el doctor Carl Looft. (Traducción de Andrés Vargas Muñoz, dedicada a los señores doctores Juan de Dios Carrasquilla, Pedro M. Ibáñez y Roberto Azuero). Revista Médica, 1898, 21 (235):113-24; Ibid., 21 (240):280-8 y números subsiguientes. 


\section{DIANA OBREGÓN}

medad de Morvan eran enfermedades diferentes o si se trataba de formas diversas de la lepra. Gabriel J. Castañeda argumentaba que todos esos nombres correspondían a una enfermedad específica producida por el bacilo de Hansen ${ }^{28}$. El debate sobre la especificidad de las enfermedades servía para subrayar la importancia de la contribución nacional a la ciencia "universal". Evaristo García, de la Sociedad de Medicina del Cauca, afirmaba que los médicos colombianos, comparados con los europeos, se encontraban en una posición especial para aclarar tales distinciones ${ }^{29}$. Juan de Dios Carrasquilla, uno de los primeros investigadores colombianos de la etiología de la lepra, se refería al "descubrimiento" del agente causal de la lepra por Hansen, como un ejemplo de la capacidad del nuevo punto de vista microbiano para explicar el origen de enfermedades que hasta entonces eran un enigma ${ }^{30}$.

Hacia finales del siglo XIX, había pocos médicos que apoyaran teorías miasmáticas, humorales o hereditarias sobre la lepra. La idea de que ésta era una enfermedad específica transmitida por un agente activo se convirtió en la teoría dominante. Nociones como clima, dieta y herencia que anteriormente los médicos consideraban como causas se convirtieron en simples antecedentes que predisponían a (o que impedían) contraer la enfermedad. Al concluir el siglo, los médicos podían burlarse sin riesgo de sus viejos profesores que enseñaban teorías hereditarias, miasmáticas y telúricas como origen de la lepra. El doctor Manuel S. Algandona de Boyacá, por ejemplo, ridiculizaba a su profesor de clínica de la Universidad Nacional quien afirmaba que la lepra era transmitida por herencia y producida por algunas topografías, por variaciones atmosféricas y por predisposiciones individuales epecíficas. De acuerdo con Algandona, estos factores no jugaban un papel específico como causas de la enfermedad; sólo el bacilo de Hansen era la "condición sine qua non" para el desarrollo de la lepra ${ }^{31}$.

Con todo, aún quedaban algunos simpatizantes de la teoría de la herencia. El doctor Alberto García, en su trabajo Nuevas observaciones sobre la lepra elefancia, su etiología y su curación, citaba como argumento contra la teoría del contagio, numerosos casos de personas que vivían en contacto estrecho con pacientes de lepra,

28 TASCÓN, L., (1887) “El mal de San Lázaro y el mal de San Antonio," Revista Médica, 11 (114): 607614; y CASTAÑEDA, G. J., (1889) "Diagnóstico diferencial entre la lepra y el mal de San Antón, Tesis para el doctorado por el Dr. Cenón Solano R.," Revista Médica, , 13 (138): 503-6; 13 (139): 531-6; y 13 (140): 571 4. En la literatura médica francesa también se debatió la cuestión por esta misma época y se estableció que se trataba de la lepra. Ver: ZAMBACO PACHA, D. Al., (1893) "Travaux Originaux: État de nos connaissances actuelles sur la lèpre," La Semaine Médicale, , 13:289-295, on p. 289.

29 GARCíA, E., (1891) "Enfermedad de Morván y lepra anestésica," Revista Médica, 15 (163-4): 512-9.

30 CARrasquilla, J. de Dios, (1889) "Disertación sobre la etiología y el contagio de la lepra", $R \boldsymbol{e}$ vista Médica, 13 (137): 441-84.

31 Algandona, M. S., (1891) "Contribución al estudio de la higiene: Historia suscinta de la lepra en Paipa," Revista Médica, 15 (166): 619-26, en pp. 625-6. 
tales como médicos, monjas y enfermeras quienes no contraían la enfermedad. ${ }^{32} \mathrm{La}$ imposibilidad de cultivar el bacilo de Hansen era otro de los argumentos de los partidarios de la doctrina de la herencia, tales como el médico Démétrius Zambaco de Constantinopla, bien conocido entre la comunidad médica colombiana ${ }^{33}$.

Más allá de la discusión sobre su origen, los médicos estaban de acuerdo en que la lepra era un problema serio. En 1886, Bernardino Medina y Gabriel J. Castañeda advertían a la Sociedad de Medicina de Bogotá que la lepra se estaba extendiendo rápidamente entre la población colombiana. ${ }^{34}$ Fuese contagiosa o hereditaria, para los médicos sólo había una respuesta para el problema de la lepra: aislamiento. Por ejemplo, Juan David Herrera, uno de los pocos médicos partidarios de la teoría de que la lepra se transmitía por herencia, recomendaba la segregación de pacientes con estricta separación de sexos para impedir la expansión de la enfermedad ${ }^{35}$.

Por lo tanto, los pacientes de lepra -opuestos a las medidas de aislamiento obligatorio- eran decididos adversarios de las teorías tanto del contagio como de la herencia. El escritor Adriano Páez, quien aparentemente había descubierto que estaba enfermo de lepra siendo cónsul de Colombia en Francia, escribió en 1878 una serie de cartas al abogado Ramón Gómez, presidente de la Junta de Beneficencia. Gómez creía que la enfermedad era heredada. En consecuencia, afirmaba que una absoluta separación de sexos debía ser impuesta entre leprosos y que el matrimonio entre ellos debía ser prohibido. Páez se oponía a estas teorías en nombre de los derechos individuales que garantizaba la constitución colombiana de $1863^{36}$. De otra parte, como típico liberal decimonónico, Páez confiaba en la ciencia. En sus memorias, publicadas después de su muerte por Juan de Dios Carrasquilla, Páez clamaba por el estudio científico de la cuestión de la lepra por médicos colombianos. De acuerdo con él, las conclusiones de investigaciones realizadas en otros países no eran adecuadas para las condiciones colombianas. Solamente a través de la experimentación científica realizada en Colombia sería posible decidir si la lepra en el país era o no contagiosa ${ }^{37}$.

Luis Carlos Pradilla, otro escritor enfermo de lepra, argumentaba en 1878 contra la teoría del contagio. Pradilla explicaba que la variedad de elefancia común en Colombia era endémica puesto que era producida por condiciones telúricas particulares. En otras palabras, la lepra era peculiar a ciertas regiones debido a circunstancias

32 MONTOYA y FLóREZ, J. B., Contribución al estudio de la lepra en Colombia (Medellín: Imprenta Editorial), pp. 106-7.

33 ZAMBACO, "Travaux Originaux," passim.

34 "Actas de las sesiones de los días 24 y 31 de Agosto de 1886," Revista Médica, 1886, 10 (107):241-243; y CASTAÑEDA, G. J., "La lepra en el estado de Antioquia," Ibid., :258-259.

35 MONTOYA, Contribución, p. 102.

36 Véanse las cartas de Páez en Gutiérrez PÉrez, A., (1925) Apuntamientos para la historia de Agua de Dios (Bogotá: Imprenta Nacional), pp. 161-165.

37 PÁEZ, A., Viaje al país del dolor (Fragmentos) en GuTIÉRREZ, Ibid., pp. 270-295, pp. 293-295. 
geográficas y climáticas específicas. Para Pradilla, la política de segregación practicada en la Europa medieval había causado la extinción de la enfermedad en ese continente debido a que este tipo de lepra era "importada" de Asia; la lepra europea había sido contagiosa antes que endémica. Pero la lepra colombiana era endémica; por lo tanto, el aislamiento de enfermos de lepra, de acuerdo con Pradilla, era completamente inútili38. Estos ilustrados pacientes argumentaban desde el viejo punto de vista de la medicina de Sydenham, según la cual cada enfermedad correspondía a un tiempo, lugar y paciente específico; las enfermedades eran resultado de una concatenación particular de causas. Esta concepción neo-hipocrática consideraba el clima y en general los factores atmosféricos como causas de epidemias y de enfermedades. ${ }^{39}$ De ahí que Páez y Pradilla insistieran en el estudio específico de la lepra en las condiciones geográficas y climáticas colombianas; para ellos, un estudio detallado de la geografía de la enfermedad indicaría que la lepra no era la misma en Europa que en Colombia.

Sin embargo, los enfermos perdieron la batalla contra el aislamiento y contra la idea de que la lepra era una enfermedad contagiosa. Hacia finales del siglo, la noción de que la lepra era producida por un microorganismo y se transmitía de individuos enfermos a sanos se convirtió en lugar común entre la comunidad médica y entre el público que tenía acceso a esta información. Aún así, el aislamiento todavía no era obligatorio. Los leprosos continuaron llegando voluntariamente a los lazaretos, huyendo de vecinos hostiles y en busca de refugio para sus penas, más que de curación o tratamiento.

\section{LAZARETOS, CARIDAD CRISTIANA Y TERAPÉUTICA}

Así como en los tiempos coloniales, durante el siglo XIX el tema de la construcción de lazaretos era un asunto político que enfrentaba al gobierno central con las provincias. En el período de la república federal (1863-1886), varios estados soberanos aprobaron leyes sobre la elefancia, autorizando a los gobernadores a fundar lazaretos locales. Este fue el origen de los lazaretos de Contratación, en el estado de Santander, y Agua de Dios en el estado de Cundinamarca. Estas leyes definían a los elefancíacos como "seres desafortunados merecedores de especial compasión por parte de las almas cristianas" y establecían limosnas y donaciones de caridad como parte del presupuesto de los lazaretos ${ }^{40}$. En 1869, el gobierno de Cundinamarca estableció una Junta de Beneficencia que debería encargarse del hospital de San Juan de Dios, de la Casa del Refugio y del lazareto de Agua de Dios, además de otras institu-

\footnotetext{
38 Montoya, Contribución, pp. 86-8.

39 Sobre este tema ver: DELACY, M., (1993) "The Conceptualization of Influenza in EighteenthCentury Britain: Specificity and Contagion" Bulletin of the History of Medicine, 67: 74-118.

40 Ley del 12 de Sep. 1867, en MONTOYA, Contribución, pp. 69-70.
} 
ciones para los pobres. La caridad cristiana era la respuesta colectiva a la enfermedad y a la pobreza. Hacia 1870 , setenta elefancíacos y sus familias, expulsados violentamente de la población de Tocaima por habitantes temerosos del contagio, encontraron refugio en Agua de Dios. Éste fue el origen de una población-lazareto que pronto adquirió la categoría de municipalidad y que creció rápidamente hasta convertirse en el mayor de los lazaretos colombianos. En 1891, los Padres Salesianos y las Hermanas de la Caridad comenzaron a prestar sus servicios a los leprosos ${ }^{41}$. Los lazaretos estaban lejos de ser instituciones médicas: su propósito era más bien separar a los enfermos del resto de la población antes que proveer asistencia médica. Como sugería Foucault para el caso de los locos, la intención de la segregación no era extinguir la enfermedad, sino mantenerla a distancia ${ }^{42}$.

Desde su fundación en 1870, todo tipo de prácticas médicas, excepto la medicina científica, coexistían en Agua de Dios ${ }^{43}$. Curanderos, homeópatas, yerbateros y empíricos abundaban en el lazareto. La medicina era un asunto privado entre médico y paciente. En este mercado, los médicos profesionales ofrecían sus "específicos" en abierta competencia con los empíricos. Los enfermos de lepra se medicaban ellos mismos y experimentaban con remedios ofrecidos por los curanderos. Algunos pacientes, ansiosos por curarse, estaban dispuestos a gastar en tratamientos el poco dinero que poseían. Entre las curas milagrosas que se ofrecían había extraños compuestos que contenían reptiles (tratamiento recomendado por médicos medievales) y otros enigmáticos remedios ${ }^{44}$. A falta de mejores opciones, la Junta de Beneficencia respaldaba estos esfuerzos. En 1880, por ejemplo, la Junta asignó recursos a los curanderos Francisco R. Ardila y a Mauritz Hoffman para ensayar sus medicinas en Agua de Dios. Sin embargo, de acuerdo con el testimonio de Antonio Gutiérrez, enfermo de lepra que escribió sus memorias como residente de Agua de Dios, la mayoría de estos practicantes eran charlatanes que sólo buscaban ganancias fáciles y que por lo general huían una vez se demostraba su incompetencia ${ }^{45}$.

Los médicos profesionales recomendaban tratamientos empíricos basados en plantas nativas, tales como otoba (Myristica otoba), zábila, guaco (Mikania guaco) y teati-

\footnotetext{
41 GUTIÉRREZ, Apuntamientos, pp. 11-12.

42 FouCAult, M., Madness and Civilization (New York: Random House, 1961/1965), p. 17.

43 Aquí no se trata de juzgar, desde un punto de vista epistemológico, la "cientificidad" o no de las prácticas médicas homeopáticas y empíricas del siglo XIX. Uso el término "científico" en su connotación sociológica: los médicos como grupo profesional excluían a otros y declaraban sus propias prácticas "científicas" oponiéndolas a otras prácticas que por definición se convirtieron en "no-científicas". Ver: GIERYN, T., (1983) "Boundary-Work and the Demarcation of Science from Non-Science: Strains and Interests in Professional Ideologies of Scientists," American Sociological Review, 48 (December):781-795.

44 Sobre tratamientos medievales para la lepra, ver: DEMAITRE, L., (1996) "The Relevance of Futility: Jordanus de Turre (fl. 1313-1335) on the Treatment of Leprosy," Bulletin of the History of Medicine, 70 (1): $25-61$.

45 GUTIÉRREZ, Apuntamientos, p. 123.
} 
na ${ }^{46}$. El remedio más popular, sin embargo, era el aceite de chaulmugra, una antigua medicina hindú para tratar la lepra. Este aceite se obtenía de las semillas de un arbusto (Taraktogenos kurzii) que crece en Burma y en la India. El aceite de chaulmugra, usado mundialmente, era la única medicina capaz de detener el proceso infeccioso hasta la era de las sulfonas en el decenio de $1940^{47}$. Este remedio, como ungüento y en forma oral, se empezó a usar desde 1880 en Agua de Dios. ${ }^{48}$ Así como ocurrió en otros países, el aceite sólo producía mejoría en algunos pacientes, pero en otros era completamente ineficaz o resultaba demasiado repulsivo para ser tolerado ${ }^{49}$. Estas dificultades y los permanentes fracasos con remedios empíricos contribuyeron a mantener la vieja creencia de que la lepra era incurable.

Por lo demás, los médicos profesionales no practicaban la medicina en los lazaretos. El primer médico que tuvo Agua de Dios fue nombrado en 1879, pero residía en Tocaima y visitaba el lazareto únicamente dos veces al mes. Durante un tiempo breve, Agua de Dios tuvo un médico residente, Marcelino Vargas, él mismo paciente de lepra. Vargas, quien murió de fiebre amarilla al año siguiente de su nombramiento, publicó un estudio con el fin de demostrar que la lepra no era contagiosa ${ }^{50}$. Los médicos considerados autoridades en lepra que publicaron trabajos sobre la enfermedad en el período anterior a la aceptación de la teoría contagionista citaban observaciones tomadas de su propia práctica privada. Sin embargo, estos médicos se basaban mayoritariamente en conocimiento teórico tomado de autores antiguos tales como Areteo ( $\mathrm{ca}$. 150 D.C.) y Galeno (130-201 D.C.) y de autores modernos como Danielssen ${ }^{51}$.

La mayoría de tales estudios trataba extensamente el tema de la terapéutica. En una época en que la medicina no se encontraba organizada como profesión, los enfermos, como clientes más que como pacientes, podían demandar cierto tipo de tratamiento y aún cierta clase de diagnóstico. Los médicos, cuyas carreras dependían de los pacientes y estaban interesados en asegurar una clientela, editaban largas y detalladas listas de remedios y de posibles curas para la lepra. De hecho, el manuscrito anónimo titulado Régimen que debe observar todo enfermo atacado de elefancia o lepra, en cualquier estado de la enfermedad publicado en 1858, terminaba con una nota anunciando que el doctor Ricardo de la Parra preparaba y vendía los remedios descritos. ${ }^{52}$ De la misma manera, la costumbre de ciertos médicos de presentar a las

\footnotetext{
46 SANDINO GROOT, W., (1889) "Plantas colombianas que se han usado contra la lepra. Teatina," Revista Médica, 13 (136):436-8.

47 FEENY, P., (1964) The Fight Against Leprosy (New York: American Leprosy Mission), p. 111.

48 "La Lepra," Anales de la Instrucción Pública en los Estados Unidos de Colombia, 1881, 2 (7): 21-41.

49 GUTIERREZ, Apuntamientos, pp. 123-124.

50 "Elefantiasis de los griegos." en MONTOYA, Contribución, pp. 95-96.

51 PARRA, R. de la, "El Zaarah de Moisés o la Elefantiasis de los Griegos", en MontoyA, Contribución, p. 66.

52 "Régimen que debe observar todo enfermo atacado de elefancia o lepra, en cualquier estado de la enfermedad" en MONTOYA, Contribución, pp. 60-61.
} 


\section{LEPRA, EXAGERACIÓN Y AUTORIDAD MÉDICA}

autoridades ejemplos de supuestos casos de lepra curados por ellos debe ser entendido como una manera de asegurar las ganancias potenciales de tales remedios. Éste parece ser el caso del doctor Esteban Pardey de Barranquilla quien en 1847 presentó al entonces presidente de la república, General Tomás Cipriano de Mosquera (18451849), dos pacientes de lepra que él había supuestamente curado ${ }^{53}$.

El interés en la terapéutica ciertamente no desapareció con la profesionalización de la medicina, pero el tema de los medicamentos tendía a ser presentado más como parte integral de una comprensión racional de las enfermedades, que como el resultado de un proceso de ensayo y error. Partidarios del contagio como modo de transmisión de la lepra, comenzaron a proponer tratamientos "racionales". Por ejemplo, Gabriel J. Castañeda abogaba por una terapia higiénica y parasiticida, y el doctor Gutiérrez y Arango de Santander promovía un tratamiento "racional" de dioxibenzina. Aunque sin duda en estos casos también existía un interés pecuniario y estos tratamientos no necesariamente eran más efectivos que las hierbas o los ungüentos, los practicantes de la medicina profesional los oponían a los remedios "sin sentido" de los charlatanes que solamente producían desesperanza entre los enfermos ${ }^{54}$. El problema de la terapéutica revela el limitado poder de los médicos en relación con la lepra y explica en parte por qué la enfermedad estaba escasamente medicalizada en las últimas décadas del siglo XIX.

\section{LA RETÓRICA DE LA EXAGERACIÓN}

Con el fin de estimar la incidencia de la lepra en Colombia, el doctor Gabriel J. Castañeda envió un cuestionario a las autoridades de los diversos municipios y presentó sus resultados a la Junta Central de Higiene en 1890. Aunque este censo fue incompleto, solamente 122 de los 920 municipios del país respondieron, ésta fue la primera estadística de lepra que se hizo en Colombia y arrojó un total de 1.724 enfermos. Los departamentos con mayor incidencia eran Santander con el 57.3\% de la población leprosa del país y Cundinamarca con el $34.8 \%$. En consecuencia, Castañeda recomendó a la Junta de Higiene y a la Academia de Medicina la construcción de leprosarios en climas secos y cálidos que, según él, no eran propensos al desarrollo de la lepra ${ }^{55}$. Sin embargo, el censo de Castañeda tuvo consecuencias que él proba-

53 PARDEY, E., "Exposición del Dr. Esteban Pardey sobre el uso del huano en la elefancia" en Ibid., pp. 59-60.

54 CASTAÑEDA, G. J., (1884) "Tratamiento parasiticida de la lepra," Revista Médica, 8 (96):513-20; y GUTIÉRREZ y ARANGO, (1891) "Observación de lepra tuberculosa: Tratamiento por la resorsina," Revista Médica, , 15 (163-4):519-32.

55 CASTAÑEDA, G. J., "Investigaciones sobre la lepra en la República de Colombia," en MONTOYA, Contribución, pp. 108-111. 
blemente no previó. El médico Abraham Aparicio, en un comentario sobre el informe de Castañeda, declaró que la propagación de la lepra era alarmante; en el caso de algunos pueblos las dos terceras partes de la población ya eran leprosas. Aunque la mayoría de las respuestas a la encuesta de Castañeda fueron proporcionadas por personas que no poseían entrenamiento médico, Aparicio se refería a esa información como "hechos de observación" y pedía al gobierno actuar urgentemente para imponer medidas higiénicas; esto es, aislamiento de los enfermos. Las sociedades de medicina de Bogotá, Cauca y Medellín indicaban que el aislamiento en Colombia nunca había sido efectivo y que los lazaretos eran únicamente aldeas donde sanos y enfermos se mezclaban sin temor. La Sociedad de Medicina del Cauca declaró que la contagiosidad de la lepra estaba demostrada por ejemplos tales como su propagación en las islas Sandwich (Hawai) y los nuevos focos de lepra en los Estados Unidos debidos a la inmigración china y noruega ${ }^{56}$. Estas referencias eran eco del absurdo temor que se apoderó de muchos en esta época, según el cuál, la supuesta epidemia de lepra originada en Hawai se extendería a Europa y a los Estados Unidos. En particular, en este último país se culpó a los chinos de ser propagadores del contagio, como parte de la campaña contra el llamado "peligro amarillo"57.

Abraham Aparicio, usando lúgubres ejemplos, afirmaba que el bacilo de la lepra resistía la putrefacción. De acuerdo con él, el microorganismo permanecía vivo en los cadáveres de quienes habían padecido la enfermedad; por lo tanto, el lugar de exclusión de los leprosos tenía que estar completamente aislado de todo movimiento social y el período de aislamiento debía ser calculado no en términos de una o dos generaciones, sino durante la "vida entera de la nación"58. Abraham Aparicio no solamente describía la lepra en términos aterradores, sino que exageró las estadísticas de Castañeda. De hecho, sin presentar nuevos datos, Aparicio llegó a afirmar que el número de leprosos colombianos era de 20.000. Para asegurar que sus colegas entendieran que ésta era ciertamente una cifra enorme, Aparicio explicaba que Colombia poseía veinte veces más leprosos que la India, que era conocida mundialmente por su alta incidencia de lepra ${ }^{59}$. Aparicio no indicaba la fuente de sus estadísticas, aparte de una breve nota: "datos presentados por el Dr. J. David Herrera"60. Sin embargo, Herrera no había adelantado ningún censo de enfermos de lepra. De acuerdo con Juan Bautista Montoya y Flórez, médico graduado en la Facultad de

56 APARICIO, A., (1890) "Propagación de la lepra elefancíaca en Colombia," Revista Médica, 14 (153): 161-5.

57 Gussow, Z., (1989) Leprosy, Racism, and Public Health: Social Policy in Chronic Disease Control (Boulder, Co.: Westview Press,), pp. 111-129.

58 APARICIO, A., (1891) “La lepra y los lazaretos," Revista Médica, , 15 (163-4):506-12, en p. 511.

59 Aunque no había datos precisos sobre la incidencia de la lepra en India, la mayoría de leprólogos hasta el decenio de 1930, afirmaba que este país presentaba una de las tasas más altas de lepra en el mundo. Ver: JEANSELME, É., (1934) La Lèpre (Paris: G. Doin), p. 75.

60 APARICIO, A., (1891) "La lepra y los lazaretos," Revista Médica, 15 (163-4): 506-12, en p. 506. 
Medicina de París, quien en 1910 estudió las estadísticas de lepra proporcionadas por sus colegas de finales del siglo XIX, "la opinión personal y privada del Dr. Herrera se convirtió en estadística pública"61. Desde ese momento, los médicos y otros grupos interesados comenzaron a anunciar un número cada vez mayor de leprosos reales o ficticios, sin que sus datos se apoyaran en un censo. Por ejemplo, en 1898, Nicanor Insignares, médico graduado de la Facultad de Medicina de París estimó el número de leprosos entre 20.000 y $30.000^{62}$. Si estas cifras fuesen correctos, significaría que entre el $0.5 \%$ y el $0.75 \%$ de una población de cerca de 4 millones sufría de lepra. Esta era una tasa muy alta si consideramos que en Noruega, en uno de los años de mayor prevalencia de la lepra (1856), ésta se estimó en $0.23 \%$ 63.

La Orden Salesiana tomó estas estadísticas ya exageradas y las aumentó a su vez. Los salesianos estaban a cargo de los lazaretos colombianos y su autoridad en estas instituciones era mucho mayor que el poder del gobierno o de la comunidad médica. El sacerdote italiano Evasio Ravagliati inició por su cuenta una campaña con el fin de recolectar fondos para construir lazaretos y llevó el total de leprosos a $50.000^{64}$. Cada grupo interesado en el problema de la lepra inventaba sus propias estadísticas de acuerdo con sus propios intereses. El objetivo de la cruzada de Ravagliati era estimular la caridad cristiana, mientras que la intención de la comunidad médica era medicalizar la lepra arrebatándosela a la filantropía. La cifra exagerada de 20.000 a 50.000 enfermos de lepra en Colombia se hizo mundialmente famosa. Reconocidos especialistas señalaban a este país como una de las regiones del mundo con mayor incidencia de lepra. Por ejemplo, el leprólogo francés Dom Sauton en su estudio de 1901 sobre la geografía de la enfermedad, afirmaba: "Colombia es la región del mundo más asolada por la lepra"; y el médico turco Démétrius Zambaco Pacha sostenía en 1914 que el tres por ciento de la población colombiana sufría de lepra65.

El médico Carlos Michelsen Uribe exhortaba al gobierno a no demorar más la solución del "grave problema de la lepra"66. Insignares expresaba su alarma por el hecho de que los colombianos no experimentaban temor alguno por la lepra, a la cual se refería como "el monstruo de las cien cabezas"67. De acuerdo con él, bellas muje-

61 Montoya, Contribución, p. 345.

62 MiCHELSEN C., resumió el trabajo de Insignares: MiChELSEN U., C,. (1898) "La lepra," Revista Médica, 21 (232): 1-29, en p. 8.

63 VogelsANG, Th. M., (1957) "The Termination of Leprosy in Norway: An Important Chapter in Norwegian Medical History; Together with a Portrait of Armauer Hansen circa 1873", International Journal of Leprosy, 25 (4): 345-51, en p. 345.

64 MONTOYA, Contribución, pp. 351-353.

65 SAUTON, D., La Lèprose (Paris: C. Naud, 1901), p. 75; y ZAMBACO, D., (1914) La lèpre a travers les siècles et les contrées (Paris: Masson), p. 609.

66 Michelsen U., C., (1898) "La lepra," Revista Médica, 21 (232): 1-29, on p. 1. en p. 8 .

67 INSIGNARES, N. citado por MiCHELSEN U. C., (1898) "La lepra," Revista Médica, , 21 (232): 1-29, 


\section{DIANA OBREGÓN}

res se casaban con leprosos y gente sana en los lazaretos establecía toda clase de relaciones con la población enferma sin repugnancia alguna. Una especie de leprofobia se apoderó de las clases altas. En 1898, miembros del "segmento educado de la sociedad Bogotana" se reunieron en el Colegio del Rosario donde expresaron su alarma por la rápida expansión de la lepra en el país ${ }^{68}$. Para ellos la lepra era un terrible azote que causaba retroceso y barbarismo en la sociedad colombiana (ver el epígrafe). La lepra comenzó a ser vista como un gran enemigo del proyecto político y cultural de las élites colombianas que consistía en entrar de lleno en lo que llamaban "la civilización".

Sin embargo, el único censo de lepra realizado en Colombia durante el siglo XIX fue el de Castañeda. Aunque incompleto, enumeró 1.724 enfermos de lepra. Cualquier otro dato era falso. La retórica de la exageración usada por los médicos se explica porque la lepra no era un problema médico en el siglo XIX. Los médicos tenían muy poco que ofrecer en términos de curación o de tratamiento. El cuidado de los leprosos estaba a cargo de órdenes religiosas y los lazaretos dependían de instituciones filantrópicas tales como la Junta de Beneficencia y la Sociedad de San Lázaro, entidad creada por personas pías para asistir a los enfermos de lepra que residían en los lazaretos. La exageración fue simplemente una estrategia para medicalizar la enfermedad. Ahora bien, los médicos quizás actuaron también bajo el influjo del terror que produjo en el decenio de 1890 en algunos países europeos y en los Estados Unidos la expansión de la lepra en Hawai ${ }^{6}$. En Colombia, el terror a la lepra promovido por los médicos en este período fue en parte producto de la influencia internacional, pero en mayor medida, fue resultado de las necesidades de la profesión médica misma.

\section{LA LEPRA: ENFERMEDAD “APARTE”}

El escándalo promovido por la profesión médica rindió sus frutos: en 1890, de acuerdo con las sugerencias de la Academia de Medicina, el parlamento colombiano aprobó las primeras leyes ordenando el aislamiento obligatorio de los enfermos de lepra. La legislación sobre lazaretos que había sido aprobada en el decenio de 1860 por los estados federados y por el gobierno central, era parte de un proyecto filantrópico. Para estos legisladores, los leprosos eran objeto de compasión y de caridad. Los deberes del estado colombiano eran fundar lazaretos como una manera de proteger a esos "desafortunados" individuos y estimular la caridad pública para que ésta se

68 Gómez, P., citado por Michelsen U., C., (1898) "La lepra," Revista Médica, 21 (232): 1-29, en pp. 17-18.

69 Gussow, Leprosy, Racism, and Public Health, pp. 111-129. 
encargara de mantenerlos ${ }^{70}$. Por el contrario, la ley de 1890 expresaba un nuevo sentido de urgencia:

\footnotetext{
"el aislamiento o secuestro de los individuos que sufren la enfermedad conocida con el nombre de elefantiasis griega [sic] es una medida higiénica de urgente necesidad pública"7!.
}

La ley exceptuaba a aquellos cuyos recursos les permitían cumplir con el aislamiento en sus propias casas de acuerdo con las reglas establecidas por las Juntas de Higiene de cada uno de los departamentos. La contravención a estas normas causaría la inmediata reclusión en el lazareto más cercano. El gobierno se comprometía a organizar tantos lazaretos como la Junta Central de Higiene considerara necesario. Sin embargo, el resultado más importante de la retórica de la exageración fue otra ley de 1890 que definió la lepra como una enfermedad "aparte" que requería consideración especial. Esta ley designó una de las islas colombianas en el Caribe o en el Pacífico para segregar allí a los leprosos de todo el país. La propuesta indicaba que toda la población leprosa que residía en los lazaretos colombianos junto con los nuevos casos que se fueran encontrando, serían enviados a la isla ${ }^{72}$. Esta propuesta se inspiraba sin duda en la isla de Molokai (Hawai), donde europeos y norteamericanos habían desarrollado un modelo de segregación colonialista de enfermos de lepra desde el decenio de $1860^{73}$.

La Junta de Higiene, la Academia de Medicina y el congreso médico de 1893 aprobaron el establecimiento de un nuevo lazareto nacional en Coiba, una isla localizada al suroeste de la costa de Panamá ${ }^{74}$. Sin embargo, hacia el final del siglo XIX, varias discusiones acerca de la conveniencia de poner en práctica tales decisiones tuvieron lugar en la Academia de Medicina. Proto Gómez y Abraham Aparicio apoyaron en forma entusiasta la propuesta de aislamiento de los leprosos colombianos en la remota isla, justificando esta política con el argumento de que los rituales de segregación antiguos y medievales respondían a principios científicos aunque quienes los practicaban ignoraran tales principios. ${ }^{75}$ Los partidarios del aislamiento riguroso también afirmaban que el ejemplo de la historia europea, especialmente la noruega, probaba que éste era el único medio efectivo para resolver el problema de la lepra ${ }^{76}$.

70 Ley del 12 de Sep. 1867, en MONTOYA, Contribución, pp. 69-70.

71 Ley 43, 14 Nov. 1890, en Ibid., pp. 112-113, en p. 112.

72 Ley 113, Dic. 1890, en Ibid., p. 113.

73 GuSsOw, Leprosy, Racism, and Public Health, pp. 85-107.

74 MONTOYA, Contribución, p. 113.

75 GÓMEZ, P., citado por MiCHELSEN U., C., (1898) "La lepra," Revista Médica, 21 (232): 1-29, en pp. 24-25; y APARICIO, A., (1891) "La lepra y los lazaretos," Revista Médica, 15 (163-4): 506-12, en p. 509.

76 "Contagiosidad de la lepra", Revista Médica, 1890, 14 (153):165-7. 


\section{DIANA OBREGÓN}

El doctor Insignares creía que un lazareto unificado en una isla, era la solución para Colombia puesto que así se garantizaría el aislamiento. Sin embargo, este médico se opuso a la propuesta porque la consideraba completamente irrealizable. Insignares comparaba la migración de la población leprosa colombiana a la isla de Coiba con una guerra civil y calificaba el posible movimiento de enfermos a través del país como una "perturbación social muy peligrosa" que debería ser evitada a toda costa, no solamente por los altos costos, sino por las posibles persecuciones en contra de los agentes del gobierno ${ }^{77}$. Las metáforas de Insignares resultaban reconocibles en la Colombia del siglo XIX, un país dividido por profundas enemistades políticas, permanentemente al borde de la guerra civil. En estas condiciones, el principal interés de las élites era la preservación del orden social; lo cual explica la preocupación de Insignares por el potencial abuso en contra de las autoridades, silenciando las víctimas reales de la persecución: los leprosos mismos.

Sin embargo, no todos los médicos veían la situación de la misma manera. Carrasquilla siempre se opuso a considerar la lepra como una enfermedad especial. En el trabajo que presentó en 1897 en el Congreso Internacional de la Lepra de Berlín, Carrasquilla criticó las propuestas que conducían a tratar a los enfermos de lepra como si fuesen criminales. Se refería a estos procedimientos como políticas de exterminación basadas en la falsa creencia de que la lepra era altamente contagiosa. Carrasquilla impugnaba la afirmación de que el aislamiento era el único método para detener la expansión de la lepra. Si las políticas de segregación tuviesen bases científicas, afirmaba, habría que aplicar los mismos métodos a todas las enfermedades infecciosas incluyendo la tuberculosis y la sífilis ${ }^{78}$.

La propuesta de construir un lazareto en la isla de Coiba jamás se realizó, no tanto por la oposición de Carrasquilla y de algunos otros médicos, sino porque los costos de la organización de un leprosario en tales condiciones eran demasiado altos para el presupuesto del gobierno colombiano. De esta manera, los enfermos de lepra permanecieron en los tres lazaretos existentes (Agua de Dios, Contratación y Caño de Loro). Sin embargo, las conclusiones del congreso de Berlín fueron ampliamente difundidas en la prensa médica colombiana, contribuyendo a reforzar el dogma del aislamiento riguroso que los médicos de hecho ya habían adoptado como método único para controlar la enfermedad 79 .

77 INSIGNARES N., citado por MiChelSEN C. U., (1898) "La lepra," Revista Médica, 21 (232): 1-29, en p. 9.

78 CARRASQuilla, J. de Dios, (1897) "Memoria sobre la Lepra Griega en Colombia," Mittheilungen und Verhandlungen der internationalen wissenschaftlichen Lepra-Conferenz zu Berlin im October 1897 vol. 1 (Berlin: Verlag von August Hirschwald), pp. 122-4.

79 “Conferencia Internacional," Revista Médica, 1898, 20 (226):213-221; 20 (227):252-5; у 20 (228): 269-82. 
A la luz de las nuevas teorías sobre el contagio y de las dudosas estadísticas epidemiológicas de los médicos, los relatos sobre la situación de los lazaretos cobraron mayor importancia. En su informe de 1896, el presidente de la Junta de Beneficencia, Francisco Montaña, síndico de Agua de Dios, describía el lazareto en los siguientes términos:

\footnotetext{
"el lazareto de Agua de Dios, tal como existe hoy, no es un establecimiento concebido para aislar gente atacada por la terrible enfermedad de la lepra... Si la enfermedad es contagiosa, circunstancia que ningún colombiano puede dudar pues la ola se esparce con una rapidez que asusta, el lazareto no solamente no se conforma con los requerimientos del aislamiento, sino que todo en él parece estar hecho para extender el contagio. El lazareto no es un hospital, no está separado por un cordón sanitario, es un pueblo donde el que quiere puede entrar o salir"80.
}

Las imágenes de los lazaretos como focos de infección causaron horror. Aunque el estado colombiano era el dueño de los terrenos de Agua de Dios, las instituciones de caridad y las órdenes religiosas jugaban allí un papel considerable. La Sociedad de San Lázaro de Bogotá colaboraba enviando medio real para complementar la ración oficial de veinticinco centavos para pacientes regulares y de cincuenta centavos para aquellos que no podían trabajar. La insuficiencia crónica del presupuesto nacional y departamental para el sostenimiento de los lazaretos se agravaba durante las guerras civiles. De hecho, la imposibilidad por parte del gobierno de proveer las raciones para los leprosos durante los conflictos, a menudo forzaba a los enfermos a dejar los lazaretos para ir a pedir limosnas en las poblaciones cercanas ${ }^{81}$. Es más, Agua de Dios fue objeto de persecución especial a propósito de dos guerras civiles: durante el levantamiento de los liberales en 1895 y durante la llamada guerra de los Mil días (1899-1902). Probablemente debido a la localización de Agua de Dios cerca de las zonas de guerra, algunos de sus residentes estuvieron implicados en las rebeliones y el pueblo sufrió las incursiones tanto del ejército como de las guerrillas liberales ${ }^{82}$. Estos incidentes muestran cómo el lazareto estaba lejos de ser una institución médica y que Agua de Dios participaba intensamente de la vida ordinaria de un pueblo colombiano de finales del siglo XIX.

La campaña de los médicos contra la lepra tuvo un resultado inesperado. La alarma que crearon en torno al problema fue tal que el gobierno colombiano invitó en 1899 al mismo Hansen con el fin de "curar la lepra o, al menos, hacerla disminuir" de acuerdo con el telegrama enviado por el presidente de la república, Manuel Antonio Sanclemente, a la Academia de Medicina, pidiendo su consejo sobre la

80 Citado por MONTOYA, Contribución, p. 148, 151.

81 Ibid., p. 149.

82 GUTIÉRREZ, Apuntamientos, pp. 29-40. 


\section{DIANA OBREGÓN}

materia. La profesión médica reaccionó con indignación indicando que la visita de Hansen era inútil puesto que su principal recomendación era el aislamiento estricto para los enfermos de lepra, solicitud que la Academia había hecho desde hacía por lo menos veinte años, sin que el gobierno la hubiese puesto en práctica ${ }^{83}$. Obviamente, Hansen nunca visitó Colombia. El célebre médico narró el incidente en sus memorias, interpretándolo como un problema de falta de recursos por parte del gobierno colombiano ${ }^{84}$. Sin embargo, el episodio revela algo más que deficiencia del presupuesto oficial. La profesión médica todavía luchaba por persuadir al gobierno de su competencia técnica y por su reconocimiento como una ocupación especial con un papel que cumplir en la sociedad colombiana. De otra parte, la estrategia de importar conocimientos o técnicas europeas para la solución de problemas locales era típica de las élites desde comienzos de la república. La reacción de los médicos a la invitación del gobierno a Hansen, su llamado a construir una ciencia nacional y sus declaraciones de independencia respecto del conocimiento "extranjero" eran parte de su lucha por afirmar su legitimidad social y su autoridad cultural.

\section{EXPERIMENTACIÓN Y MEDICINA CIENTÍFICA EN LOS LAZARETOS}

Evidentemente la exageración retórica no fue la única respuesta de la profesión médica frente al problema de la lepra en Colombia. La comunidad médica también contaba con las armas del conocimiento científico. Por lo demás, los practicantes de la medicina científica ya no se limitaban a atender su clientela privada, sino que estaban en condiciones de realizar actividades que les significaran reconocimiento por parte de sus pares. De hecho, una de las consecuencias de la profesionalización de la medicina fue la apertura de oportunidades para realizar investigación. Así como sus colegas europeos, los médicos colombianos también realizaron experimentos en humanos intentando determinar el modo de transmisión de la lepra. En 1893, el médico Daniel Vega adelantó en Agua de Dios algunos experimentos sobre los cuales aparentemente se mantuvo reserva. Vega inoculó productos leprosos tales como suero y sangre en catorce niños sanos, voluntarios, residentes en el lazareto ${ }^{85}$. Aunque doce de ellos desarrollaron lepra posteriormente, el experimento no sirvió para probar si la lepra se transmitía o no por inoculación. Puesto que los padres eran pacientes de lepra, los niños podían haber contraído la enfermedad por herencia, a través del medio ambiente o por transmisión directa o indirecta. Los experimentos, aparte de su dudoso mérito científico, muestran las deficientes condiciones en las

\footnotetext{
83 “Informe del Secretario Bienal," Revista Médica, 1899, 21 (243):362-73, en p. 367.

84 HANSEN, G. A., (1976) The Memories and Reflections of Dr. G. Armauer Hansen (Würzburg: German Leprosy Relief Association), p. 125.

85 MONTOYA, Contribución, p. 295.
} 
cuales vivían los pacientes de lepra y sus familias en los lazaretos. La mayoría de los pacientes descreía la teoría del contagio; quizás por ello estaban dispuestos a dar su consentimiento para que sus hijos fuesen inoculados. Por lo demás, la promesa de que los niños recibirían la ración diaria como leprosos desde el momento de las inoculaciones, independientemente de que desarrollaran o no la enfermedad, constituyó sin duda un enorme atractivo para padres indigentes. Igualmente, los experimentos ponen en evidencia la actitud cientificista de los médicos del siglo XIX: el nombre sacrosanto de la ciencia justificaba tales prácticas. De esta manera, los habitantes de Agua de Dios se convirtieron en objetos de experimentación; sus cuerpos podían ser usados para verificar o para descartar enunciados científicos; en una palabra, sus cuerpos comenzaban a ser medicalizados.

Otro ejemplo permite apreciar algunos de los cambios generados en la relación médico-paciente con el desarrollo de la medicina científica. La convicción cada vez más generalizada de que la lepra era producida por un microorganismo generó esperanzas entre algunos médicos y pacientes en cuanto a sus posibilidades de tratamiento y curación. El desarrollo de la bacteriología produjo un optimismo sin precedentes en la historia de la medicina, según el cual las enfermedades parecían poder ser curadas por métodos específicos. Siendo la lepra un problema de primera importancia para la comunidad médica colombiana, la búsqueda de un método terapéutico basado en doctrinas científicas parecía estar al alcance de la mano.

El éxito de las antitoxinas contra el tétano y contra la difteria en la época dorada de la bacteriología, hizo pensar que métodos semejantes podrían ser aplicados para enfermedades como la lepra. La seroterapia se basaba en un principio explicado por el alemán Emil von Behring y por el japonés Shibasaburo Kitasato en 1890. Estos científicos inocularon conejos y ratones con cultivos de tétano y encontraron que su inmunidad dependía de la capacidad del suero de neutralizar las toxinas producidas por el bacilo del tétano. Esta capacidad era durable y además podía ser transferida a otros animales. Por algún tiempo, la seroterapia fue vista como la panacea contra las enfermedades infecciosas hasta el primer accidente fatal ocurrido en $1896^{86}$. Además, los científicos pronto encontraron que en muchos casos, no había diferencia entre el suero inmune y el normal; ambos podían eventualmente conferir inmunidad. En consecuencia, el suero no parecía ser un tratamiento específico y la seroterapia fue abandonada ${ }^{87}$.

En Colombia, uno de los primeros médicos que aplicó la seroterapia en pacientes de lepra fue Carlos Putnam, médico graduado de la Facultad de Medicina de Lyon, quien en 1895 probó el nuevo tratamiento en el lazareto de Agua de Dios. Sin embargo, el experimento tuvo que ser interrumpido cuando Juan de Dios Carrasquilla,

86 Como medida preventiva, el médico alemán Langerhans inoculó antitoxinas a su hijo en perfecta salud, causándole la muerte. Ver: Moulin, A. M., (1991) Le dernier langage de la médecine: Histoire de_l'immunologie de Pasteur au Sida (Paris: Presses Universitaires de France), pp. 68-69, 143.

87 Bulloch, W., The History of Bacteriology (New York: Dover, 1938/1979), pp. 261-264. 


\section{DIANA OBREGÓN}

quien también aplicaba la seroterapia a sus pacientes de lepra en Bogotá, reclamó ante la Academia de Medicina su derecho a ser considerado como el primero que había usado exitosamente este tratamiento ${ }^{88}$. Aparentemente, el patólogo vienés Victor Babes había intentado la seroterapia inoculando enfermos de lepra con suero de perros que habían sido inmunizados contra la tuberculosis; este suero producía un efecto tónico en los pacientes ${ }^{89}$. Carrasquilla preparaba el suero directamente de la sangre de los pacientes de lepra usando caballos; su método se inspiraba en la analogía entre la lepra y la sífilis ${ }^{90}$. La Academia de Medicina otorgó a Carrasquilla la prioridad por el uso terapéutico del suero anti-leproso y el gobierno creó el Instituto Seroterapéutico para proseguir estas investigaciones ${ }^{91}$. El médico Pedro Pablo Nates, junto con cinco estudiantes de medicina como asistentes, inició los experimentos con el "suero Carrasquilla" en Agua de Dios. A pesar de la retórica oficial que presentaba a Carrasquilla como "el salvador" de los leprosos, los resultados eran diversos: algunos pacientes mejoraban, mientras que en otros los síntomas se agravaban ${ }^{92}$. Estos experimentos tuvieron amplia difusión: por ejemplo, en la Real Academia de Medicina de Madrid se informó sobre el "método Carrasquilla" en 189693. En 1897, Carrasquilla asistió como delegado de Colombia al Congreso Internacional de la Lepra de Berlín donde la seroterapia fue uno de los temas de discusión ${ }^{94}$. Este congreso puso de presente que el "suero Carrasquilla" había sido puesto a prueba por los investigadores alemanes Edward Arning y Albert Neisser y por científicos de Argelia, Londres y Copenhage; también había sido usado en el hospital de Saint Louis de París, en la Escuela Hematológica de Viena y en el hospital para leprosos de Robben Island en Sur Africa. Sin embargo, el juicio del congreso de Berlín no fue favorable para Carrasquilla; la Academia Colombiana de Medicina dictaminó que su método era inocuo y, aunque lo estimulaba a continuar sus investigaciones, el gobierno le retiró su apoyo ${ }^{95}$.

\footnotetext{
88 GUTIÉRREZ, Apuntamientos, p. 31.

89 ROGERS L., y MUIR E., (1925) Leprosy (New York: William Wood,), p. 250.

90 GARCía MEDinA, P., (1895) "Comunicaciones sobre el empleo de la seroterapia en la lepra, hechas a la Academia Nacional de Medicina de Bogotá (Colombia) por el señor doctor Juan de D. Carrasquilla L.," Revista Médica, 18 (204):296-308, en pp. 296-8 (nota), 307-8.

91 RICO, E., (1925) "Doctor Juan de Dios Carrasquilla," Repertorio de Medicina y Cirugía, 16-7 (187):304-13, en p. 307.

92 GUTIÉRREZ, Apuntamientos, p. 33.

93 "Actas de sesiones literarias," Anales de la Real Academia de Medicina, 1896, 16:61-69; ver también: SAN MARTín BACAICOA, I., (1966) La lepra en la España del siglo XIX Cuadernos Valencianos de Historia de la Medicina y de la Ciencia (Valencia), pp. 85-86.

94 CARRASQuilla, J. de Dios, (1897) "Memoria sobre la Lepra Griega en Colombia," Mittheilungen und Verhandlungen der internationalen wissenschaftichen Lepra-Conferenz zu Berlin im October 1897 vol. 1 (Berlin: Verlag von August Hirschwald), pp. 81-124.

95 "Conferencia Internacional sobre la lepra, habida en Berlín del 11 al 16 de Octubre de 1897" (Extracto de las discusiones hecho por el Dr. E. Kummer para la Semaine Médicale de París, traducido por el Dr. M.N. Lobo), Revista Médica, 1898, 20 (228): 269-82), en pp. 271-5.
} 
Ahora bien, los detalles del uso de la seroterapia en Colombia muestran el nuevo rol de la profesión médica. Putnam tuvo que suspender sus experimentos en Agua de Dios mientras el asunto de la seroterapia se definía en otra instancia: la Academia de Medicina. Hasta entonces, debido a que la práctica médica estaba escasamente regulada, el éxito o fracaso de los tratamientos empíricos ofrecidos por médicos o por curanderos permanecía como un asunto privado. Con la profesionalización de la medicina, las cuestiones relativas a la terapéutica pasaron a ser del dominio de un cuerpo profesional que poseía el poder de aprobar o de rechazar una determinada práctica.

\section{CONCLUSIONES}

A finales del siglo XIX, cuando la práctica de la medicina occidental se volvió "científica", la lepra se convirtió en objeto médico. Al mismo tiempo, la práctica de la medicina pasó a ser una profesión en Colombia. De esta manera, los médicos colombianos excluyeron todo tipo de conocimiento no-profesional sobre la lepra como no-científico. La obra de renombrados leprólogos europeos fue traducida y se hizo accesible a la profesión médica que se convirtió así en el único vocero autorizado para referirse a las complejidades de la enfermedad. Así mismo, la teoría microbiana con su explicación de que las enfermedades eran producidas por microorganismos específicos se convirtió en la explicación dominante. Sin embargo, la profesión médica tendió a desconocer otros saberes, ignorando la experiencia e información que los pacientes de lepra poseían acerca de la enfermedad. Este fue el caso de la noción de que la enfermedad, aunque contagiosa, era difícil de transmitir de un ser humano a otro. De acuerdo con saberes pre-bacteriológicos, la enfermedad era producida por una gran cantidad de causas, el contagio entre ellas. Al carecer de la noción de una única causa específica, no había diferencia entre tomar todas las precauciones o ninguna. No había prohibiciones especiales para salir de los lazaretos, o si las había no se aplicaban. Hacia finales del siglo XIX, con la nueva comprensión contagionista de la lepra, la situación cambió radicalmente. La idea de que la enfermedad era contagiosa y que se estaba extendiendo rápidamente, hizo de la lepra una seria amenaza para el proyecto civilizador que las élites se habían trazado. La comunidad médica formuló el problema de la lepra en lo que creía eran términos científicos universales. Los médicos colombianos también desarrollaron una retórica de la urgencia de forjar una "medicina nacional" a medida que se convertían en grupo profesional. Sin embargo, las teorías microbianas sobre el origen de la lepra contribuyeron a justificar en términos científicos, viejas prácticas de exclusión.

Por lo demás, los médicos exageraron el número de contagiados como una estrategia para medicalizar la lepra. Algunos médicos contribuyeron a crear pánico acerca de la lepra en una época en que ésta no era un tema exclusivamente médico. La pro- 


\section{DIANA OBREGÓN}

fesión médica necesitaba convencer a la sociedad de su exclusiva posesión de competencia científica para tratar adecuadamente la enfermedad; por lo tanto, debía demostrar que la filantropía había sido incapaz de manejar el problema, que las cifras de leprosos aumentaban en vez de disminuir. En fin, a finales del siglo XIX, cuando la medicina se convirtió en profesión en Colombia, la lepra fue uno de los medios que los médicos usaron para afirmar su autoridad científica y para aumentar su poder. 